Promoting resilient economies by exploring insurance potential for facing coastal flooding and erosion: evidence from Italy, Spain, France and United Kingdom

Osiel González Dávila, Mavra Stithou, Gianluca Pescaroli, Luca Pietrantoni, Phoebe Koundouri, Pedro Díaz-Simal, Bénédicte Rulleau, Nabil Touli, François Hissel and Edmund Penning-Rowsell September 2013

Centre for Climate Change Economics and Policy Working Paper No. 147

Grantham Research Institute on Climate Change and the Environment Working Paper No. 127 
The Centre for Climate Change Economics and Policy (CCCEP) was established by the University of Leeds and the London School of Economics and Political Science in 2008 to advance public and private action on climate change through innovative, rigorous research. The Centre is funded by the UK Economic and Social Research Council and has five inter-linked research programmes:

1. Developing climate science and economics

2. Climate change governance for a new global deal

3. Adaptation to climate change and human development

4. Governments, markets and climate change mitigation

5. The Munich Re Programme - Evaluating the economics of climate risks and opportunities in the insurance sector

More information about the Centre for Climate Change Economics and Policy can be found at: http://www.cccep.ac.uk.

The Grantham Research Institute on Climate Change and the Environment was established by the London School of Economics and Political Science in 2008 to bring together international expertise on economics, finance, geography, the environment, international development and political economy to create a worldleading centre for policy-relevant research and training in climate change and the environment. The Institute is funded by the Grantham Foundation for the Protection of the Environment and the Global Green Growth Institute, and has five research programmes:

1. Global response strategies

2. Green growth

3. Practical aspects of climate policy

4. Adaptation and development

5. Resource security

More information about the Grantham Research Institute on Climate Change and the Environment can be found at: http://www.lse.ac.uk/grantham.

This working paper is intended to stimulate discussion within the research community and among users of research, and its content may have been submitted for publication in academic journals. It has been reviewed by at least one internal referee before publication. The views expressed in this paper represent those of the author(s) and do not necessarily represent those of the host institutions or funders. 


\title{
Promoting resilient economies by exploring insurance potential for facing coastal flooding and erosion: evidence from Italy, Spain, France and United Kingdom
}

\author{
Osiel González Dávila, ${ }^{\mathrm{a}, \mathrm{b}}$ Mavra Stithou, ${ }^{\mathrm{b}}$ Gianluca Pescaroli, ${ }^{\mathrm{c}}$ Luca Pietrantoni, ${ }^{\mathrm{c}}$ \\ Phoebe Koundouri, ${ }^{\mathrm{b}}$ Pedro Díaz-Simal, ${ }^{\mathrm{d}}$ Bénédicte Rulleau, ${ }^{\mathrm{e}}$ Nabil Touili, ${ }^{\mathrm{e}}$ François \\ Hissel $^{\mathrm{f}}$ and Edmund Penning-Rowsell ${ }^{\mathrm{g}}$ \\ ${ }^{1}$ Corresponding Author, E-mail address: osielgonzalezdavila@ hotmail.com, Phone: +30-(0)69395 87 \\ 871 \\ ${ }^{\mathrm{b}}$ Athens University of Economics and Business-Research Centre, 76, Patission Str. 10434, Athens, \\ Greece \\ ${ }^{\mathrm{c}}$ Alma Mater Studiorum - Università di Bologna, Via Zamboni n.33, 40126 Bologna, Italy

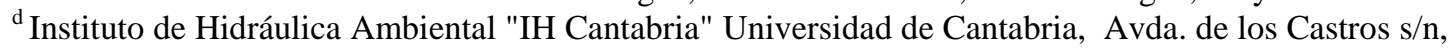 \\ Santander 39005,Spain \\ ${ }^{\mathrm{e}}$ Versailles Saint-Quentin-en-Yvelines University; Sciences Sociales et Humanités; Centre for \\ Economics and Ethics of the Environment and Development, 47 Bld Vauban 78047 Guyancourt \\ Cedex, France \\ ${ }^{f}$ Centre d'Etudes Techniques Maritimes et Fluviales, 2, Boulevard Gambetta, BP 60039, 60321 - \\ Compiegne Cedex, France \\ ${ }^{\mathrm{g}}$ Middlesex University; School of Health and Social Sciences, Flood Hazard Research Centre, \\ Queensway, Enfield, Middlesex, EN3 4SA, UK
}

Abstract Insurance against natural perils such as flooding can be considered a significant element in coastal management. It can offer not only much-needed support to accelerate economic and social recovery following a disaster (coastal resilience) but also contribute to impact limitation by using pricing or restrictions on availability of coverage to discourage new development in hazard-prone areas. Insurance can affect the redistribution of damage costs across the population and through time, both in the short and long term. Policies of damage reduction are linked to mitigation measures for the properties (old or new buildings) by changing the depth-damage relationship while the long-run risk impacts could affect the overall damage function by discouraging new buildings in high risk areas. This paper will provide an overview of the main theoretical perspectives on insurance in flood risk management. Four different European contexts will be analysed. Data are derived from surveys and interviews conducted in France, United Kingdom, Italy and Spain.

Keywords: coastal flooding, coastal erosion, insurance, resilience 


\section{Introduction}

Coastal areas are great zones of settlement and play a vital role in the wealth of many nations, but large stretches of the European coasts are already threatened by coastal erosion and flooding. It is anticipated that climate change and sea-level rise will increase the frequency and severity of flooding and erosion events. Coastal protection and water management in lowlands have been the most common responses, and have been concerned to 'keep water out,' 'defend property from water' and 'live on dry land.' However, there has been a change in attitude towards those measures in response to the growing risk and uncertainty generated by climate change. As traditional technical flood and erosion defences have shown their limits, what society expects from defences is changing. A wider portfolio of structural measures to reduce flood hazard and non-structural measures (e.g. land-use planning, insurance schemes etc. that aim to reduce flood vulnerability) to adapt to environmental change is needed. Treby et al. (2006) observed that hazard management shifted from physical hazards alone to include the socio-economic, political and behavioural patterns of the affected population. Similarly, Crichton (2008) emphasizes that "risk management must recognise that controlling exposure and vulnerability can be much more costeffective than simply trying to control the hazard." The contribution of insurance in flood risk management can be multi-dimensional as it can transfer risk, enhance risk awareness, contribute to the reduction of flood vulnerability, support the rebound of socio-economic systems and hence the resilience of coastal communities. Therefore, insurance is of critical importance to society since it affects the redistribution of the cost of damage across the population and through time (Clark, 1998).

Flood insurance could be represented by the Risk Triangle in Figure 1. Risk encompasses a combination of hazard, exposure and vulnerability and it is articulated as the area of the triangle, the sides of which represent hazard, vulnerability and exposure. In this framework if any one element (side of the triangle) increases/decreases, then the amount of risk will increase/decrease accordingly (Crichton, 2001).

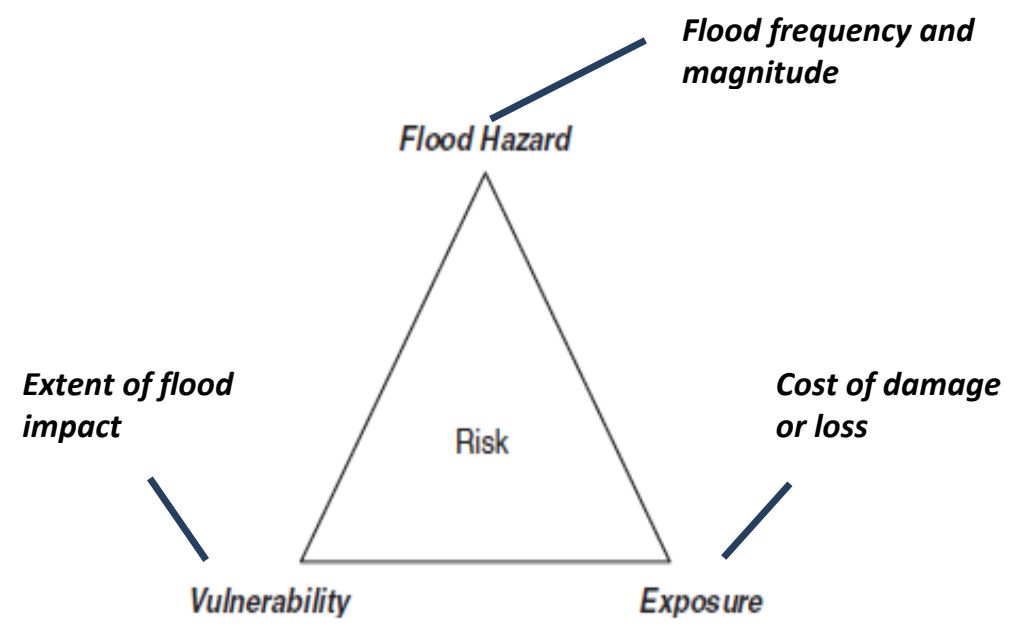

FIGURE 1: The Risk Triangle (Source Crichton and Mounsey, 1997) 
According to Crichton and Mounsey (1997), vulnerability could indicate the extent to which a given hazard would impact on a property by reason of its materials or its layout. Therefore, insurance could impact on vulnerability by introducing a condition on coverage/policy condition. Insurance arrangements for flood risk may require households to undertake measures that mitigate damage or stimulate households to undertake precautionary measures voluntarily (Kunreuther and Pauly, 2006). These mitigation measures may limit damage during floods and be complementary to traditional flood protection (Botzen et al., 2009). Vulnerability can be decreased by offering lower premiums for properties that take action to reduce their exposure to flood risk. A wide range of construction measures can be used to reduce flooding risk while integrating on site solutions of flood avoidance, flood resistance, flood resilience and flood repairable (Communities and Local Government, 2007). Moreover, it is possible to undertake 'resistance measures' to prevent floodwater reaching the inside of properties (for example door-guards) which can contribute to $£ 10,000-£ 50,000$ cost of avoided damage depending on the flood depth (Bowker, 2007). Hence, if insurance is directly related to measures that change the depthdamage relationship in properties, the possible impact of a flood should be lower and both the repair costs and the time that the properties are uninhabitable should fall.

Exposure, from an insurance perspective, is a function of the value of the asset/property at risk and its cost if damaged or lost. Mitigation can play a critical role in reducing exposure to future floods which translates into lower flood insurance premiums if rates reflect risk (Czajkowski et al., 2012). For example, Botzen's et al. (2009) examine the willingness of homeowners in the Netherlands to undertake measures that mitigate flood damage in exchange for benefits on hypothetical flood insurance policies. The results indicate that many homeowners are willing to make investments in mitigation (e.g., water barriers) due to the premium discount on the flood insurance policy, while reductions in (absolute) flood risk due to mitigation are especially large. In this sense, insurance has the potential for activating an ex-ante mitigation mechanism through policy conditions or by encouraging measures to reduce the occurrence, severity or impact of a natural peril.

The structure and development of economic activity on coastal areas prone to flooding could be influenced as well by insurance in the long run. Dawson et al. (2011) argue that market and planning instruments such as insurance impact on flood plain geography and development preferences. The authors highlight significant increases in the cost of flood insurance result in property blight for buildings in the highest risk areas, determining a different land use. Thus, insurance can increase risk awareness if the premium is linked to the possible risk. Treby et al. (2006) while criticizing the reality of insurance market in UK, note that if a clear link is established between flood risk and property value, this information might be used to raise awareness and incentive the mitigation actions of home owners. Similarly, Filatova et al. (2011) pinpoint that increased individual coastal flood risk awareness is an important option to decrease flooding risk in coast zones, as knowledge about the probability of disaster does not imply awareness about consequences. Insurance against flooding as a financial mechanism may serve as a measure to communicate this risk and to persuade people to integrate it by making its purchase compulsory in flood prone zones. In particular, housing markets in countries where flood insurance is mandatory reveal a decrease of prices due to insurance pressure on individual 
budgets. In that way, flood insurance conveys risk information to participants in the coastal housing market.

Natsios (1991 p.111), states that policy makers could use market incentives as a very effective way of changing social behaviour. Financial (dis)incentives can promote risk reduction and mitigation through insurance against flood (Treby et al.2006). Insurance creates incentives by linking coverage to mitigation actions or by not entering an area to provide coverage. For example, people and business activity will have either to adapt to insurance's prerequisite for mitigation or to bear totally the risk of flooding in case that coverage is not offered.

Insurance can be seen as a catastrophe recovery (promoting socio-economic resilience), cost limitation and management tool (Clark, 1998) by sharing risk and lowering the burden on tax-supported disaster relief programs, influencing decisions to locate in the floodplain and by encouraging the use of measures to minimize damage (Doornkamp, 1995; Arnell, 2000). Insurance can further reduce susceptibility to flooding by encouraging communities to adopt a broad range of flood loss reduction strategies. For example, in the United States the Federal Emergency Management Agency promotes the Community Rating System or $\mathrm{CRS}^{1}$ program. It is voluntary and designed to give flood insurance premium rate reductions as an incentive in communities that implement comprehensive flood damage reduction programs. The three main goals of the CRS are to reduce flood losses, facilitate accurate insurance rating, and promote the awareness of flood insurance.

Our work will compare four European Case studies analysed within the Theseus Project (FP7.2009-1, Contract 244104, www.theseusproject.eu) to explore how societies perceive risk of coastal hazards and insurance schemes. Evidence will provide a complete and updated overview of applications or possible adoption of insurance schemes within the European Union.

\section{Case study areas}

Our research used qualitative and quantitative methodologies to integrate different academic approaches to flood insurance. The heterogeneity of input coming from field work is due to the differences in the study sites. The most appropriate method was selected in each place. Thus, a common frame of questions was not possible. Semi-structured interviews were conducted Spain, France and the UK. A survey was implemented in Italy.

\subsection{Cesenatico and Bellocchio (Italy)}

Cesenatico and Bellocchio are located in the Emilia Romagna's coast and flooding insurance is not available there. Even if the two sites are relatively near in space, the different ecological and cultural context can determine a different impact of insurance on field. Cesenatico is located near the cities of Rimini and Riccione, and is nationally and internationally known as tourist destination for the number of events and activities promoted during summer season. Bellocchio area is part of the Po River

\footnotetext{
${ }^{1}$ More information is available in the following link: http://www.fema.gov/business/nfip/crs.shtm
} 
Delta Park included in UNESCO's World Heritage List and is characterized most for the presence of second houses especially from the city of Ferrara.

Erosion episodes there were evident since the early XX century. Since the 1980s new strategies have been developed to substitute the traditional forms of coastal defence with flexible methods. The need for new solutions and know-how lead the Emilia Romagna Region to participate in major projects financed by the European Community (Region Emilia Romagna 2011). Attention has been given to an integrated coastal management approach with intervention lead to qualify and monitor the local environment. Such integrated approach for selection of a sustainable coastal defence scheme is presented in Zanuttigh et al. (2005).

\subsubsection{Survey design}

The survey aimed to explore risk perception and risk preparedness in Cesenatico and Bellocchio. The main research efforts were concentrated in Cesenatico because of its higher population density, geographical homogeneity and political relevance. Anonymity and confidentiality were assured to all participants. A five pages questionnaire was applied in Cesenatico in March 2011 and required 15 minutes to be completed. Similarly, a four pages questionnaire was applied in Bellocchio and required 10 minutes to be completed. In Cesenatico, the majority of the questionnaires ware self-administered (167/191). In Bellocchio, most of the material was obtained through interviewer-administrated questionnaires (61/76). Using the informal interview methodology, standard answers included complementary comments or notes (Russell-Bernard 2006). Descriptive statistics were obtained using the programme SPSS V.19. Univariate Anova was used to confront personal data of gender and social housing condition, while the Pearson's $r$ coefficient was used for age factor. A factorial analysis was developed to reduce the number of variables considered in the risk perception. Those statistical elements where applied only in Cesenatico. The measures used in the questionnaire are:

$>$ Individual and collective preparedness was evaluated on scale from 1-10, where 1 represented the lowest value and 10 the highest value in the scale.

$>$ Past experience of flood Open questions asked to recall the year, period and duration of flooding experiences followed by multiple choice questions. Answers were evaluated on a 1-10 range and focused on the degree a previous flooding have caused financial damages $(1=$ no financial damage, $10=$ considerable damages), as well as the degree that ordinary life was disturbed $(1=$ no disturbance at all, $10=$ considerable disturbance).

Perceived effectiveness of countermeasures considered the systems in use and the possible strategies to implement for facing future flooding. Respondents were asked to express their opinion of effectiveness in relation with specific measures adopted at local level and the answers were evaluated on a 1-10 range $(1=$ not effective at all, $10=$ extremely effective). The participant's grade of agreement with the development of possible strategies was measured using a Likert scale from 1-5 (1= completely disagree, $5=$ completely agree $)$. That section contained a particular question on the possible use of insurance, in the form: How much do you agree with the strategy of insurance coverage in case 
of damages for managing in the future the problem of coastal erosion and the risk of coastal flooding?

Socio Demographics investigated general information about respondents.

\subsubsection{Results}

191 questionnaires were collected in Cesenatico. 58.6\% of the respondents were male and the mean age was 39.3 years $(\mathrm{SD}=14.1) .25 .1 \%$ of the participants had medium school diploma, $62 \%$ high school diploma and $12.8 \%$ a degree. $31.4 \%$ of respondents owned commercial businesses near the seaside while $45.5 \%$ worked in seaside related activities. $44.8 \%$ reside near the seaside. In Bellocchio 76 questionnaires were collected. $51.4 \%$ were female respondents and the mean age was 45 years $(\mathrm{SD}=$ 15.29). $10.7 \%$ of the respondents had only elementary school and were usually older people. $20 \%$ of the participants had medium school diploma, 56\% higher school diploma and $13.3 \%$ had a degree. $40.5 \%$ of respondents own commercial businesses near the seaside, while $70.3 \%$ of participants live near the seaside. Bellocchio had a significant percentage $(22.4 \%)$ of second house owners which were mostly holiday residences or bought after the earthquake that hit the Emilia-Romagna region in 2012.

Citizens in Cesenatico felt not enough informed about flooding risk $(\mathrm{M}=4.31$, range 1 to 10$)$ or able to protect themselves and their family $(M=4.72$, range 1 to 10$)$. Similarly, weak information levels $(\mathrm{M}=3.43$, range 1 to 10$)$ and ability to protect themselves and their family ( $M=3.77$, range 1 to 10) was reported in Bellocchio.

Beach nourishment was perceived as the most effective coastal defence in Cesenatico $(\mathrm{M}=4.94$ range 1 to 10$)$, followed by transversal barriers $(\mathrm{M}=4.29)$, and submerged breakwaters $(\mathrm{M}=4.20)$. Insurance coverage was considered as the most effective innovative mitigation option ( $\mathrm{M}=4.00$, rage 1 to 5 ) followed by restrictive land use planning $(\mathrm{M}=3.78)$. Converting bathing establishment and retreat from the coastline were not perceived very effective $(\mathrm{M}=2.61)$. Table 1 presents the descriptive statistics of insurance-related questions in Cesenatico (range from absolutely disagree to absolutely agree).

Table 1- Descriptive statistics of insurance related question

\begin{tabular}{ll}
\hline Mean & 4 \\
Std. Dev. & 1.265 \\
Frequencies (\%) & \\
1- Absolutely disagree & $14(8 \%)$ \\
2- Partly disagree & $9(5 \%)$ \\
3- Neutral & $30(17 \%)$ \\
4- Partly agree & $34(19 \%)$ \\
5- Absolutely agree & $90(51 \%)$ \\
Observations & $177(100 \%)^{\mathrm{a}}$ \\
\hline
\end{tabular}

${ }^{\mathrm{a}}$ Due to missing values

The situation was different in Bellocchio. Interventions on the sewer systems were perceived as the most effective mitigation measure ( $M=8$, range from 1 to 10$)$, as many problems were associated with bad water drainage. Other interventions such as sand nourishment $(\mathrm{M}=6.52)$, wave farms $(\mathrm{M}=6.31)$ and transverse rocky cliffs $\underline{(M=6.2)}$ were perceived as sufficiently effective. Submerged barriers had lower 
values ( $M=5.2)$. As happened in Cesenatico, neutral values were attributed to the destination of a different use to particular buildings near the coastlines $(M=3.7)$ and retreat from the coastline $(M=3.58)$. Respondents highlighted the preservation of natural habitat as the best mitigation option for the future $(M=4.28$, in scale one to five where one represented totally disagree and five totally agree). The possibility to increase restrictive land use planning was considered good as well ( $M=4.14$, $\underline{\mathrm{DS}=1.06) \text {, while the access to flood insurance was considered slightly neutral }}$ $\underline{\mathrm{M}=3.41, \mathrm{DS}=1.39) \text {. }}$

It has to be highlighted that in Bellocchio many people who gave low values to insurance explained their choice with comments on high taxation pressure, low trust in institutions at national level, or low trust in insurance companies. These elements were not identified in our questionnaires, and suggest further research with ad-hoc enquires, as well as the influence of political believes or socio-economic status. Thus, the overall difference in the values of perceived utility could be influenced by the different amount of people that was involved in the analysis, but also by the specific context that determine the local pattern of flooding. For instance, Cesenatico is subject to the inundation of the central area of "Porto Canale" (Canal Port) for joint sea ingression and pressure from riversides, with damages to tourist infrastructures, shops and commercial activities that could be effectively mitigated by insurances. In Bellocchio there have been episodes of flooding especially in the village of Porto Garibaldi, but in general the most common problems were related to sewer systems that do not have enough carrying capacity during heavy raining. This point emerges clearly if personal experience of flooding is considered. As Table 2 reports, in Bellocchio the perception of economic damages $(\mathrm{M}=5.09, \mathrm{SD}=3.49 ; \mathrm{N}=20)$ and discomforts $(\mathrm{M}=4.33, \mathrm{SD}=3.41 ; \mathrm{N}=20)$ is significantly lower than in Cesenatico $(\mathrm{M}=5.67, \mathrm{SD}=3.34, \mathrm{~N}=95 ; \mathrm{M}=5.99 \mathrm{SD}=3.09, \mathrm{~N}=94)$. Furthermore, the fear for economic losses during the flood period was much higher in Cesenatico ( $M=6.72$, $\mathrm{SD}=3.05 ; \mathrm{N}=102)$ than in Bellocchio $(\mathrm{M}=3.47, \mathrm{SD}=3.72 ; \mathrm{N}=21)$.

Table 2- Comparison of Economic Damages and Discomfort experienced in Cesenatico and Bellocchio, range 1 to 10

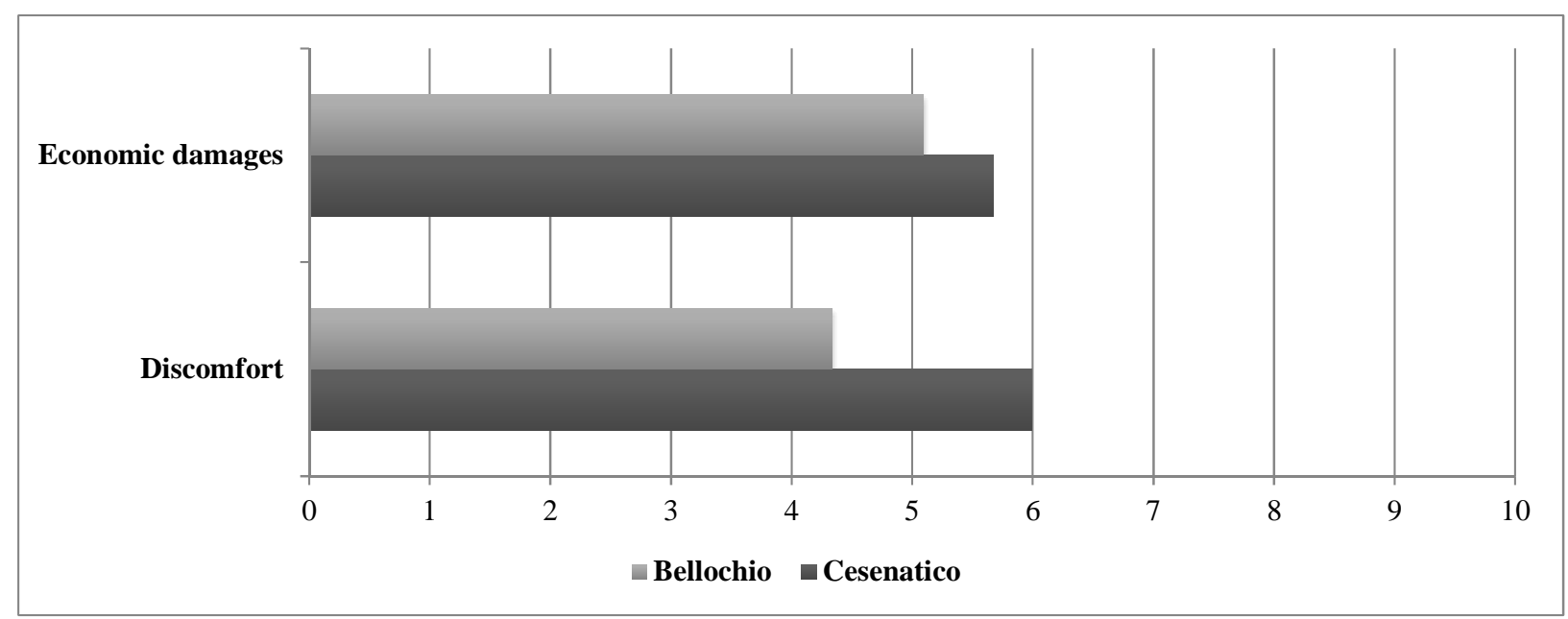

The values of economic damages and discomfort were correlated with perceived effectiveness of insurance as mitigation option in Cesenatico and Bellocchio using Spearman's Coefficient. In Cesenatico a weak relationship between economic damage 
and insurance effectiveness exists $(\mathrm{r}=.267)$ as well as the fear of economic losses during the flood $(\mathrm{r}=.244)$, while the value of discomfort is not very relevant $(\mathrm{r}=.167)$. The values in Bellocchio differ heavily. The relation between economic damage and insurance is inverse $(\mathrm{r}=-.556)$, the fear of economic losses is weakly inversely related $(\mathrm{r}=-.217)$ and discomfort seems not to influence the results $(\mathrm{r}=-.09)$. This result was unexpected and a coherent explanation within the data of our questionnaire was not possible. For example, in Bellocchio further analysis showed a high correlation between perceived discomfort and interventions in the sewer systems $(r=.769)$ and a weak correlation between economic damages and interventions in the sewer systems $(\mathrm{r}=.235)$, but these results does not explain such a difference between our case studies. The main hypothesis is that specific features of the context in Bellocchio are determinant in relating personal experience to possible mitigation measures, while the limited number of people that experienced flood also influenced the analysis. The development of evidence on the perception of flood mitigation measures requires a wider integration between a quantitative methodology and a qualitative approach (as the ethnography) in order to provide stronger suggestions for the analysis.

Thus, the focus on Cesenatico is justified by the wider number of citizens involved in the research and for the higher values attributed to insurance as mitigation option for the future. Table 3 contains a description of variables included in the regression analysis. Table 4 present the results. They confirm that personal experience of flooding and financial damage, and fear for economic losses during the flood could increase the probability of agreeing for insurance coverage with higher certainty. Other variables relationships such as "How much informed you are about flooding risk in Cesenatico" and "How much you feel able to protect yourself and your family in case of flooding" were also tested without being significant.

Table 3-Description of variables included in regression analysis

\begin{tabular}{ll} 
Variable & Description \\
Educ & Education $(1=$ high level of education, $0=$ low level of education) \\
Age & Age of respondent \\
Floodexp & Have you ever personally experienced a flooding? $(1=$ Yes, $0=\mathrm{No})$ \\
Flooddam & $\begin{array}{l}\text { In what degree a previous flooding have caused to you financial damages? (1= } \\
\text { no financial damages to } 10=\text { considerable financial damages) }\end{array}$ \\
Subgates & $\begin{array}{l}\text { How efficient do you think is the measure of "Porte Vinciane" (Harbor Gates) to } \\
\text { reduce the risk of coastal flooding and erosion? (1= not efficient at all to } 10= \\
\text { totally efficient) }\end{array}$ \\
Alert & $\begin{array}{l}\text { How useful do you think is the service of alert on your mobile? (1= not useful at } \\
\text { all to } 10=\text { absolutely useful) }\end{array}$ \\
Control & $\begin{array}{l}\text { In what degree the potential risks associated with the phenomenon of coastal } \\
\text { erosion could be under control? } \\
\text { (1= totally uncontrollable to } 10=\text { totally controllable) }\end{array}$ \\
\hline
\end{tabular}


Table 4: Regression analysis of Insurance in Cesenatico

\begin{tabular}{lll}
\hline Variable & $\begin{array}{l}\text { Ordered Probit } \\
\text { Model_1 }\end{array}$ & $\begin{array}{l}\text { Ordered Probit } \\
\text { Model_2 }\end{array}$ \\
\hline Educ & $-0.691(0.386)^{*}$ & $-0.794(0.476)^{*}$ \\
Age & $-0.001(0.009)$ & $-0.002(0.010)$ \\
Floodexp & $1.080(0.372)^{* * *}$ & $0.814(0.403)^{* *}$ \\
Flooddam & $0.103(0.048)^{* *}$ & $0.119(0.065)^{*}$ \\
Subgates & & $-0.112(0.062)^{*}$ \\
Alert & & $0.092(0.059)$ \\
Control & & $-0.089(0.108)$ \\
Model Diagnostics & -85.971 & -61.530 \\
Log likelihood & 0.07 & 0.13 \\
Pseudo R ${ }^{2}$ & 9.55 & 19.13 \\
Wald Chi ${ }^{2}$ & 0.048 & 0.007 \\
Prob > chi & 81 & 62 \\
\hline N & & \\
\hline
\end{tabular}

${ }^{\mathrm{a}}$ Robust standard errors in parentheses. (*) indicates significant at $10 \%$; (**) indicates significant at $5 \% ;(* * *)$ indicates significant at $1 \%$.

\subsection{Santander (Spain)}

Santander Bay is the best natural shelter in the northern coast of Spain. Its 22.5 sq. km allows a complex network of interacting activities that summarizes much of the problems and use conflicts typical from coastal areas. The bay was fringed with marshes that have been filled during past centuries, in order to generate space for economic activities, residential use and infrastructures, substantially modifying the hydrodynamics of the estuary and the biological framework. Its quick evolution is easily perceived by affected agents. A population of around 250.000 inhabitants is settled nearby. This represents a huge pressure for the area. The need to trade-off spatial resources assignments among different conflicting uses as port infrastructures, urban development, natural areas and recreational areas (beaches) have originated a very rich social debate.

\subsubsection{Brief comments on the insurance market}

The influence of insurance on agents' behaviour can be summarized as follows: most of real state property is insured due to financial firms' pressures and to the risk memory derived from past experiences on urban fires. Insurance covers both personal responsibilities and damage to properties. The attraction of activities towards the coast line and the expectation to be protected with public funds and hard infrastructures has resulted in an over-exposition to environmental risks. Firms claim that the insurance regulation that includes incentive based threshold for damages represents a problem for firms that have to self-cover non negligible risks sometimes compromising the financial stability of the firm. Finally, the existence of a background public system coverage for catastrophic and non-insured responsibilities for third people has created a discussion on the actual coverage of the damages that invites agents to speculate and delay the funds supply requiring emergency support from the state to attend until the responsibilities are clear. The weakness of the law courts due to delays in Spain is another source of concern for firms.

The Insurance Compensation Consortium (Consorcio de Compensación de Seguros) is an instrument of the Spanish insurance sector. Its aim is to pay indemnities deriving from extraordinary risks to insured persons who, having paid the corresponding 
surcharges, are not covered for an extraordinary risk in their insurance policy or in case an insurance company cannot meet its indemnification obligations because it is bankrupt or in liquidation. For the purposes of the Consortium cover, losses will be considered to be direct damage to persons and property, as well as the loss of profits when these are the result of said damages to property and represent an alteration of the normal results of the economic activity of the insured party and derive from the stoppage, suspension, or reduction of productive processes or the business of said activity.

\subsubsection{Risks covered}

The Spanish insurance system does not condition the protection to a certain number of insured people or a wide expanse of territory. An event might only affect a sole insured party, who would have full rights to being indemnified without an official declaration of "catastrophe" or "catastrophic area." The risk that causes most damage in Spain is flood. Different kinds of flooding are included in insurance coverage such as the flooding of ground as a result of rainfall or thawing snow; from water emanating from lakes with a natural outlet, etc. Likewise, the cover includes the battering of coastal waters, even if there is no flooding. However, are excluded from this concept of flooding the results of rainfall falling directly on the insured risk, or that collected by its roof, its drainage network or its patios, and neither is that flooding which is occasioned by the breakage of dams, canals, sewerage systems or other artificial subterranean water courses, unless such breakage is consequence of an extraordinary event covered by the Consortium.

\subsubsection{Description of the interview process}

A focus group and two rounds of interviews were conducted in summer 2010 and 2012 to public and private agents. The first group included Coastal managers from Central and Regional Governments, Port Authority Managers and local county representatives. Among the second group port operators, Chamber of Commerce experts, and general firms using coastal areas were questioned about their perception of risk exposition, about their experience about past damages, and about their conceptual model on the problem when climate change is involved. Private agents were specifically questioned about their interaction with insurance and their expectations about insurance coverage and incentives in the future.

\subsubsection{Results}

The interviewees reported that the water rises and falls as much as $50 \mathrm{~m}$. Although extreme events have occurred (The strongest "Gale" was about 10 years ago with winds up to $178 \mathrm{~km} / \mathrm{h}$ destroying trees and five years ago a wave destroyed the Chiqui Restaurant) they do not perceive any trauma to society. No significant changes in the architectural design due to these events were reported. However, they reckon that if more extreme events occur this will force the construction of new facilities in companies operating close to the port because they store things that need preservation (agrifood products, fertilizers and alloy linings). Therefore companies should have better maintained facilities to minimize the risk of loss.

They report having more damages in recent years and almost all "consorciables" (covered by the consortium). Therefore, they consider that in the near future insurance 
cost will be much higher and with more exclusion clauses. They mentioned that insurance companies have not yet internalized the risks variation over time and as the consortium compensation insurance will have to keep in mind that each time will face more charges. They do not perceive significant differences between insurance companies and it is evident from the interviews that several stakeholders are not fully aware of the Consortium's insurance activities. They mention that although insurance is required by law some insurance companies will not be able to respond to the customer. As the financial situation deteriorates, excuses for not paying claims are becoming more and more common. In case of a dispute with an insurance company the wait for Tribunal to settle the case can take seven or eight years. They mentioned that this if forcing them to be more diligent and consider self-insurance, increase prevention and being more cautious.

Respondents mentioned that public goods are not insured and there is no formal recovery plan in Santander. Nevertheless, in the North of Spain there are emergency funds to solve flooding problems immediately. There are "Confederaciones Hidrográficas" (adminsitrative agencies) and one of their functions is to develop land use planning both in rivers and in the coast in order to deal with flooding and erosion. In case of emergency, state funds are earmarked for this purpose. The respondents are not aware of the existence of an evacuation plan. However, they mentioned that they are trying to hire a University to determine measures to be considered, protocols in cases of floods that come from water in Cantabria.

The Spanish Meteorological Agency passes daily information for $72 \mathrm{~h}$ forecasts to the Civil Protection Directorate. The Directorate is responsible for notifying the state forces, national police and fire-fighters and gives information through the media to society in general. There are constant weather information updates in the port area. The services coordination centre of the port authority provides the information; this affects the time of arrival of the ships, unloading or not depends on the product.

\subsection{Results from the Gironde Estuary (France)}

\subsubsection{Background and socioeconomic profiling}

The Gironde estuary is the largest in Europe with an area of $635 \mathrm{~km}^{2}$. It is formed by the confluence of the Garonne and Dordogne rivers. Between the mouth and the confluence point are a series of small islands, mainly vineyards or protected areas. Most of the land surrounding the estuary is rural. The flood-prone area covers about $800 \mathrm{~km}^{2}$, of which $644 \mathrm{~km}^{2}$ are agricultural areas $\left(80 \mathrm{~km}^{2}\right.$ are made of highly valued wine crops, i.e., $8 \%$ of total Bordeaux vineyards), $65 \mathrm{~km}^{2}$ are urban and artificial surfaces and $54 \mathrm{~km}^{2}$ are forest and semi-natural areas. In terms of population density, the site is quite heterogeneous: among the 220,000 people living in the flood-prone area, 164,000 live in Bordeaux area (population census of 2009). The city of Bordeaux welcomes 2.5 million tourists each year.

The most recent flood occurred in February 2010: the storm Xynthia affected 62 French cities ( 27 in the study area). It resulted in 53 deaths and caused $€ 1.5$ billion in damage in France. The city of Bordeaux was affected by storms in December 1999 (windstorm Martin, parts of the Blayais Nuclear Power Plant located on the banks of the Gironde estuary were flooded), March 1988 (Bordeaux partially flooded), May 1982 (1,500 families struck in Bordeaux), etc. The flood risk is an important aspect in 
spatial planning. National regulations identify areas where building is allowed. The management of flood defences is far less organized: the dikes belong to many owners having different levels of safety practices. A new flood mitigation plan is being discussed by all role-players in the estuary that will tackle different challenges (engineering protection, social measures, communication, etc.) and will be supported by an economic analysis.

\subsubsection{Insurance context}

In France, floods are the natural disasters that cause the most damage (OECD, 2006). The French insurance system combines 1) "standard" insurance contracts and 2) since 1982, a quite unique compensation scheme aiming to cover damages due to natural disasters of abnormal intensity. This scheme, called "Cat-Nat" (for "Catastrophes Naturelles"), is based on mandatory premium surcharge collected by insurers from non-life insurance policyholders in a uniform (i.e. independent on the risk faced) amount that the government determines. The government provides reinsurance. This Cat-Nat scheme guarantees compensation for affected people.

\subsubsection{Methodology employed to collect the survey}

The data collection consisted of semi-structured interviews, mostly based on indirect questions. 42 interviews were conducted among which 11 included questions on insurance. The aim was to understand damage compensation mechanisms to cover individuals and businesses as well as their impact on flood risk management. The sampling approach was based on a pre-selected representative sample of people from governmental and non-governmental institutions involved in flood risk management at the communal, local and regional scales and a snowball sample.

\subsubsection{Results}

A risk manager informed that the Risk Prevention Group ministry is responsible of dealing with risk issues. They provide information on prevention policies, the "Barnier fund," the compensations questions and the predictable flooding risk prevention plans (PPRI) constraints. He claimed that if some people are not covered by insurance, public institutions focused on risk studies contact them. He considers that people should ask public risk studies institutions to improve their own knowledge about risk insurance. Another risk manager mentioned that insurance companies are especially interested in risk mapping to identify risk at the territory level. Insurance companies work tightly with the Risk Prevention Group ministry to estimate the population at the flood risk areas. Those actions might increase knowledge at national level while the insurance companies are pooling risks (cooperative management of risks) if an event occurs. Implementing the pooling is interesting because tools and knowledge are shared. In contrast, a flood risk planner informed that the available knowledge about the compensation accounts balance resulting from a flood event is not shared. There is no information about the costs of dykes' reparation after storm Xynthia or about how much the insurance companies had paid then. In general, there are some information problems. The interviewees mentioned that insurance regulations are not sufficiently clear for individuals. A flood risk manager explained that people somehow estimate risks. However, even if they want to protect themselves they are not fully aware of the territory vulnerability. Many people have no past 
experience with flood risks and there is also some false sense of security resulting from holding a "full insurance." Thus, insurance as a tool for flood risk management could affect the awareness of people who own a very good insurance. Nevertheless, a flood risk planner considers that the role of insurance companies is becoming increasingly important since they communicate their insurance holders how to act if a flooding event occurs (for example, he got from his company a brochure with precautions to face the risk). A flood risk planner explained that the insurance system based in quantitative approach to calculate only the direct damages of the flood event could not always help for recovery for the businesses affected. The insurance system named Cat-Nat, calculate the direct damages but not the indirect ones. He considered that the population is more vulnerable now that in the past due to the huge value of goods existing now in coastal areas. According to harbour administrators, the port is like any company, and all companies are covered by insurance. They hold risk insurance for nautical engines, for cars and for buildings and materials: gantry cranes, etc. They select insurance depending on its cost. Another harbour administrator mentioned that they are not covered by insurance for operational breakdown failure (if an accident makes them not able to continue functioning and generate income). The reason is the high insurance cost for breakdown failure (since the risks are huge, the premiums are consequently high).

A rural planner mentioned that people living at PPRI areas are constrained by the PPRI: they cannot build new houses or extend their present houses. Therefore, they have 3 options: accept those regulations and keep living there, move to another place or to build against the PPRI regulations. In the last case, the insurance companies will not accept to cover them as they built in illegality in regard of PPRI regulations. A risk manager explained that if you are located at a risk area where there is no PPRI and you are flooded 4 or 5 times, insurance companies can apply a weighty extra premium. What is the reason? If no PPRI is made, you will pay too much. Contrarily, if the PPRI is made, you will be asked to take some precautions and your house will not be destroyed. With the PPRI you are covered by insurance and there is no huge extra premium if flooded.

Some actions are implemented to help the populations impacted by the event. For example, during the storm Xynthia temporary roofs were provided and people were relocated. He reckoned that in order to recover from the trauma, psychological aid is more critical than the financial or material help. In addition, psychological help is cheaper than the financial one. Thus, psychological monitoring must be taken into account. An environmental planner explained that insurance arrangements exist for the agricultural farming but not for the forest. The exploiters of the forest are not satisfied about the insurance arrangement of the law of 2012 (due to the high premiums) and the situation seems to be jammed at this point. Therefore, the foresters' insurance purchase will be too low but also because the insurance companies would not like to cover high risk areas.

\subsection{Results relating to South Devon (UK)}

\subsubsection{The general insurance context}

The insurance industry in the UK is extremely well developed and flood insurance is widely available. There are three basic components to this industry: 1) a system of 
brokers who sell insurance cover on a commission basis but take no risk; 2) Underwriters in the form of insurance companies who take on risk and write the insurance policies and pay out to those covered who suffer from flood damage, and 3) re-insurers who cover losses that are too large for the 'retail' insurers to manage.

The insurance companies, who take the risk themselves and generally provide cover across a range of services, are large companies. In most cases these insurance companies do not only take on risk in the UK, but are large European or global insurers. The re-insurance companies, generally operate internationally, from whom insurance companies buy reinsurance to protect themselves against major claims.

The whole of the sector is composed of private companies operating in the commercial marketplace. In general there is no state subsidy or protection for insurance companies in the UK, although there are many agreements and a degree of regulation that controls the marketplace.

\subsubsection{The methods used}

For the UK, there was no survey of those at risk or of insurance companies to investigate the issue of insurance and resilience. This was mainly because flood insurance is widely available, so many questions asked in other THESEUS locations were not relevant, and also because the views of those in the industry were gathered in a different way. This involved recording discussions with a wide range of relevant stakeholders during a series of meetings and workshops held by the UK's HM Treasury to investigate the cessation of the arrangement known as the Statement of Principles (see below).

\subsubsection{Results: the incidence of flood insurance}

Insurance companies in the UK are private companies. Their purpose is to make profits for the shareholders, and in general insurance is highly profitable in the UK, although that does not necessarily apply to the flood component of that insurance.

Insurance companies are regulated by the Financial Services Authority (FSA) and have the Association of British insurers (ABI) as their trade organisation. Many agreements with government are between the Association and government, and the FSA will require that insurance companies have certain levels of capital reserves so as to be viable in the marketplace. The relationship between government and the ABI is governed by what is called the Statement of Principles, whereby government has agreed to maintain its expenditure on flood risk management in return for insurance companies continuing to offer cover to most households and businesses in areas of significant flood risk.

This flood insurance is therefore widespread. The only situation in practice (as opposed to the formal situation in the Statement of Principles) where insurance companies currently refuse to provide insurance is domestic properties built in flood risk areas since 2009. Insurance companies are not obligated to take on new customers, so one way of "refusing" cover (and reducing liability) is to set the premium so high (or with such a large deductible) that the customer cannot afford that insurance. 
Our discussants informed us that insurance cover for flooding is provided as a part of general household and business insurance. No insurance is available for erosion. Flood insurance is bundled in composite insurance policies along with fire, theft and other natural perils. In general, competition is not based on the type and extent of policies, but on price and other characteristics. Insurance of domestic and commercial properties is completely voluntary, except where properties are the subject of a mortgage. The main driver for households adopting insurance coverage is therefore the fact that mortgage companies require householders to insure their property against most perils, and without mortgage finance most people in the UK cannot afford to buy domestic properties.

In the non-residential sector the principal motivation of businesses taking out insurance for business continuity with regard to flooding (and other perils) is "getting back to business" as soon as possible after some disturbing event and the protection of assets at risk. No insurance policies appear to be provided at a community level. There may be circumstances where people get together to buy insurance for a group of properties, but this is not typical and is not encouraged by insurance companies.

The most important factor affecting premiums is the value of the property at risk. The risk of flooding and other such considerations are becoming more important, but within a bundled policy it is not easy - for us or for policy holders - to determine exactly which factors are most important in determining premium levels. Insurance companies will take into consideration other adaptation mechanisms (such as structural defences, spatial planning etc.) but only in a very indirect way in terms of how they influence the risk attached to of a floodplain area. Usually this risk will only be measured at the level of the postcode, whereby all properties within a postcode area are given the same level of risk.

\subsubsection{Results: flood insurance and the resilience of flood insurers}

The term 'resilience' here needs to be seen in two ways. First, there is the consideration as to how resilient are the flood insurance arrangements and, secondly, how does flood insurance assist or promote the resilience (to flooding) of those who choose to insure against flooding. There is a great deal of data on the former aspect, but little on the latter.

With respect to whether the concept of resilience is useful when designing insurance schemes, our discussants agreed that it is useful because insurance arrangements need to be robust or insurance companies will fail if there are multiple claims. And such failures have occurred in the past, principally in the United States of America in the 1920s, and resulted from youthful companies incurring substantial losses in paying out large claims before they had built up reserves.

The situation in the UK now is that the financial regulator requires insurance companies to have large reserves such as they can cover at least the one in 200 year event. There is also the provision, noted above, for insurance companies to re-insure their risks, therefore spreading the threat of failure away from direct marketplace for retail flood insurance. 
A number of other mechanisms is used to protect insurance companies from failure, principally the spreading of risk across a number of perils (such that no insurance company would cover just flood alone), and ensuring that any individual portfolio of risks is balanced in that it does not include just those properties which are at greatest risk. Also the Statement of Principles continues the tradition whereby even properties that are free from flood risk pay flood insurance as part of their bundled policies. The result is a massive cross-subsidy between those without risk to those at risk (as much as Euros 1.2bn per annum), and this has been the practice in UK flood insurance for over 50 years. In this respect the resilience of insurance companies is maximised, and it is true to say that no insurance company in the UK has foundered in the last five decades. Resilience is, as it were, "built in".

\subsubsection{Results: flood insurance and the resilience of those at risk}

Those in the insurance industry consider it helpful to insurance arrangements if coastal communities can maximise their own resilience, by wise spatial planning and building regulations, and sensible evacuation plans for use in the event of a flood requiring emergency response. This, self-evidently, increases their profitability by reducing future claims; if the current practice continues of not significantly reducing premiums when risk is reduced, then this also adds to profitability. And in the eyes of the insurance industry, increased profitability means increased resilience (of their operation).

But two challenges here were identified. The first is that when seeking to encourage policy owners to continue their efforts to protect themselves against flooding (i.e. increase their resilience by reducing their vulnerability), and not rely solely on insurance cover to compensate them for the losses, there is a danger that insurance becomes an excuse for inaction. This is compounded by the fact that most flood insurance in the UK covers the cross-subsidy mentioned above, so that those at significant risk pay lower premiums than would be justified if they were adequately to cover the claims that are made. Indeed, there is an in-built incentive for those at risk of flooding who are insured to remain at risk, and even to increase their vulnerability, because the penalty of flood damage is covered by their insurance premium for which they pay far too low a sum.

In the UK the signal provided by flood insurance is therefore far too weak, as a result of this cross-subsidy, to be a deterrent to occupy risky locations, and therefore communities are made less resilient by flood insurance in this way than otherwise would be the case. This may appear a surprising result, that flood insurance decreases resilience, but there is ample evidence from the UK that this is the case.

The signal would be stronger if insurance companies made their risk computations more transparent, but this would reduce each company's commercial advantage so it is not done: much information is commercially sensitive and should not be revealed to third parties. And insurance companies are less concerned with risk at a particular location (the concern of the property owner) than with total risks in its whole portfolio. For example, in Plymouth insurance companies will not necessarily look in detail at flood risk in individual locations/properties, but more look at the general pattern of flood risk overall. Nevertheless, insurance companies have postcode information on flood risk for the whole of the UK, and that applies to Plymouth as 
well as anywhere else. For large commercial properties insurance companies would do site surveys to determine risk more accurately, because the potential for inaccurate estimation of risk is more dangerous with large commercial properties. Here the signal may be stronger.

The second challenge is again ensuring that insurance companies are sound and will not fail when circumstances lead to multiple claims across a wide range of policy owners. Moral hazard is always a danger in any insurance scheme, and the resilience of that scheme is threatened if it multiplies. Our discussants mentioned that just as they expect car owners to ensure that their cars are properly serviced and roadworthy, so they expect coastal communities at least try to make their properties as resilient as possible, if resistance is impossible. They see insurance as a partnership between the insurance company and a property owner, rather than a one-way bet for the latter.

Countering this finding that flood insurance can increase vulnerability and thereby reduce resilience is the recognition that insurance promotes recovery from hazardous events, by providing rapid damage compensation. Such compensation also reduces trauma and (probably) the ill-health effects of flooding, although the adverse effects of struggling to get compensation from insurers is not to be dismissed. Insurance cover can also prevent businesses "going under" after floods through compensation for lost trade: "bounce-back" is enhanced. But not everyone is insured: the most vulnerable are not made more resilient as they do not insure; insurance is thus not universally beneficial in promoting resilience.

\section{Conclusions and policy implications}

It is considered that a combination of measures that limit damage and reduce the probability of flooding could be the most effective way of preventing the occurrence of large flood damages. Policy-makers may create incentives by giving individuals alternatives to make location choices that reduce flood risk in coastal areas. Individual coastal flood risk awareness can be increased by risk communication, financial mechanisms (such as insurance) and engineering solutions (Filatova et al., 2011). As Parker (1995) notes "the goal of floodplain management should not be flood loss reduction per se, but to take steps to ensure that loss exposure and vulnerabilities are minimized." According to Crichton (2007), the insurance industry will have an increasingly important role in helping society to adapt and become more resilient. However, the success of insurance schemes depend on how flood insurance cover is arranged within a country, how sophisticated the country's insurers are in mapping flood risks and how much the insurers are regulated by government. Government's intervention is of vital importance: policies interact with the formation of risk behaviour and are capable of creating incentives. Crichton (2008) explains some ways in which insurers can help:

1. Assistance with identifying areas at risk.

2. Catastrophe modelling.

3. Economic incentives to discourage construction in the flood plain.

4. Collection of data on the costs of flood damage to feed into benefit cost appraisals for flood management schemes.

5. Promotion of resilient reinstatement techniques.

6. Promotion of temporary defence solutions. 
Some of these activities are already happening in our study sites in Spain, France and the UK as we reported in the previous sections. Nevertheless, although the role of insurance as a vulnerability reduction and resilience enhancement mechanism has been emphasized, it should be acknowledged that its effectiveness is conditional on a number of parameters such as socio-economic and physical changes and governance arrangements.

First of all, the French insurance system described above is not specific to flood risk and thus remains, obviously, vulnerable in case simultaneous events occur. The State, as a final reinsurer, ensures the regulation of this system. From a resilience point of view, this reduces the financial vulnerability and ensures compensation for victims facing strong flood events. But, in terms of risk management, the reduction of this financial vulnerability has collateral effects:

* Since the mandatory premium surcharge is uniform, it is 1) nor representative of the risk faced, 2) nor an incentive to reduce risk for policy-holders living in high-risk areas, 3) nor a limitation to urbanisation of these high-risk areas;

* Since the State unilaterally sets, pre-event, the rate of the extra-premium and, postevent, the insurance company's deductible, this limits the intervention of private insurers and may thus lead them to trivialise risks insurance.

From a resilience point of view, and within the general framework of risk management, the current French insurance system does in consequence not seem to support the reduction of individuals' risks on their own, nor the adoption of business continuity plans. Furthermore, it does not support prevention policies since the latter introduce planning restrictions on building. The maintenance of the current compensation system will rely on land use planning measures aiming to reduce risk exposure in high-risk zones. Since the current system focuses mainly on the financial vulnerability, its negative collateral effects may impact the resilience of risk management, as shown by the recurrence of natural disasters. The increasing risks faced by people and assets on the one hand and the growing activation of government's guarantee raise concerns about the vulnerability of this system.

The UK example - where flood insurance is widespread - shows that this insurance can both enhance and reduce resilience, the former by encouraging or perpetuating exposure, as a form of moral hazard, and the latter by enhancing recovery. It is certainly not universally beneficial and is only sustainable if it subsidises those at risk who make claims with the premiums from a much larger pool of participants. Also, the notion that one can develop a flood insurance programme or option for a particular community (say a single at-risk coastal town) is deeply flawed; for that system to be both profitable and sustainable a nationwide insurance market is required (or even a global system), insuring a number of perils. Coastal managers need to clearly understand this point.

A solid conclusion on the adoption of flood insurance in the Italian case studies requires further research. Indeed, flood insurance as mitigation option has to be contextualized in the cultural, political and communitarian setting where insurance has to be developed. The weak correlations we found suggest that citizen's appreciation of insurance could be related to many more variables than the ones included in our questionnaires. While the influence of individual experience, 
education levels and local flood history was effectively measured, many other patterns that could relate local behaviours to overall decision-making were not considered. Similarly, low trust levels in insurance companies, national institutions and market regulations appeared in informal interviews but were not registered in our questionnaires. Cultural attitudes, individual perception and experience, as well as specific features of local communities, could determine the success or failure of insurance as resilience strategy. Even if a Nation-scale strategy is implemented, significant differences in its perceived utility have to be expected even among nearby areas as shown between Cesenatico and Bellocchio.

Some final lessons can be learnt from our ground testing. The role of access to information on risk communication is one of the constraints. Stakeholders in Spain and France mentioned that more efforts should be done in order to improve the access to information in relation not only on flood risks but also on insurance options. The role of insurance companies is becoming increasingly important since they communicate their insurance holders how to act if a flooding event occurs (for example, providing brochures with precautions to face the risk). Impact limitation is evident in France and the UK due to different insurance pricing or restrictions on the availability of coverage in high risk areas. Nevertheless, there are various challenges that need to be addressed. In Spain, where insurance is required by law as the financial situation deteriorates, excuses for not paying claims are becoming more and more common. The weakness of the law courts due to delays in Spain is another source of concern for firms. This is forcing them to be more diligent and consider self-insurance, increase prevention and being more cautious. Another challenge is to encourage policy owners to continue their efforts to protect themselves against flooding, and not rely solely on insurance cover to compensate them for the losses.

Our research thus shows that many factors affect the way that insurance may or may not mitigate risk and make European coasts safer, not least the role of governments, markets and risk information: this is far from straightforward. We therefore see the need for more research here, not least in Italy, to give greater clarity as to the precise role of insurance within portfolios of the necessary risk mitigation measures, and as to its different likely effectiveness in the varied insurance arrangements we currently see across Europe.

\section{Acknowledgments}

The support of the European Commission through FP7.2009-1, Contract 244104 THESEUS ("Innovative technologies for safer European coasts in a changing climate"), is gratefully acknowledged. 


\section{References}

Arnell, N. (2000). Flood insurance. In: Parker, D.J. (Ed.), Floods. Routledge, London, pp. 412- 424 .

Botzen, W.J.W., Aerts, J.C.J.H., and J.C.J.M. van den Bergh (2009). Willingness of homeowners to mitigate climate risk through insurance. Ecological Economics, Volume 68, Issues 8-9, 15 June 2009, Pages 2265-2277.

Bowker, P. Independent Consultant (2007). Flood resistance and resilience solutions: an $R \& D$ scoping study. R\&D Technical Report. Joint Defra/EA Flood and Coastal Erosion Risk Management R\&D Programme. Published by the Department for Environment, Food and Rural Affairs, May, 2007.

Clark, M. J. (1998). Flood Insurance as a Management Strategy for UK Coastal Resilience. Journal article The Geographical Journal, Vol. 164.

Communities and Local Government, Defra and Environment Agency (2007). Improving the flood performance of new buildings, Flood resilient construction. Consortium managed by CIRIA Department for Communities and Local Government: London.

Crichton, D. (2008). Role of Insurance in Reducing Flood Risk. The Geneva Papers, $33,117-132$.

Crichton, D. (2007). What can cities do to increase resilience? Philosophical Transactions of the Royal Society 10.1098, 1-11.

Crichton, D. (2001). The Implications of Climate Change for the Insurance Industry. Building Research Establishment, Watford, England.

Crichton, D., Mounsey, C. (1997). How the Insurance Industry will use its flood research. In: Proceedings of the Third MAFF Conference of Coastal and River Engineers, 131-134.

Czajkowski, J., Kunreuther,H., Michel-Kerjan, E. (2012). A Methodological Approach for Pricing Flood Insurance and Evaluating Loss Reduction Measures: Application to Texas. White Paper January 2012.

Dawson, R.J., Ball, T., Werritty, J., Werritty, A., Hall, J.W., Roche, N. (2011). Assessing the effectiveness of non-structural flood management measures in the Thames Estuary under conditions of socio-economic and environmental change. Global Environ. Change (2011), doi:10.1016/ j.gloenvcha.2011.01.013-In press.

Doornkamp, J.C. (1995). Perception and reality in the provision of insurance against natural perils in the UK. Transactions of the Institute of British Geographers 20 (1), 68-80.

Filatova, T., J. P.M. Mulder, and A. van der Veen (2011). Coastal risk management: How to motivate individual economic decisions to lower flood risk? Ocean \& Coastal Management, 54 (2), 164-172.

Kunreuther H. \& M. Pauly (2006). Rules rather than discretion: Lessons from Hurricane Katrina. Journal of Risk and Uncertainty, Springer, 33(1), 101-116, September (From the issue entitled "Special Issue on Natural Disaster Risks").

Natsios, S. (1991). Economic incentives and disaster mitigation. In: Kreimer, A., Munasinghe, M. (Eds.), Managing Natural Disasters and the Environment. Proceedings of a Colloquium sponsored by the World Bank, 27-28 June 1990. World Bank, Washington, DC, pp. 111-114

Regione Emilia Romagna - Assessorato sicurezza territoriale, difesa del suolo e della costa, Protezione Civile (2011), Studio per ottimizzare la gestione del litorale di Cesenatico Nord. Regione Emilia Romagna. Bologna. 
Treby, E. J., Clark, M. J. and S. J. Priest (2006). Confronting flood risk: Implications for insurance and risk transfer. Journal of Environmental Management Volume 81 (4), 351-359.

Zanuttigh, B., Martinelli, L., Lamberti, A., Moschella, P., Hawkins, S., Marzetti, S., Ceccherelli, V.U. (2005) Environmental design of coastal defence in Lido di Dante, Italy. Coastal Engineering 52, 1089- 1125. 